\title{
Coeliac Disease in a Girl: A Case Report
}

\author{
Begum $N^{1}$, Khatoon $S^{2}$, Deb $S^{3}$, Sultana $S^{4}$
}

\begin{abstract}
Coeliac disease is an autoimmune disorder that occurs in genetically predisposed people of all ages from middle infancy to onwards. It is a disease in which the mucosal lining of the small intestine is damaged in response to ingestion of gluten and similar proteins, which are found in wheat, oats, rye, barley and other grains. Symptoms include chronic diarrhoea, failure to thrive and fatigue; however these may be absent and symptoms in other organ systems have been reported. In this case report, a 6 year-old girl presented with recurrent diarrhoea with growth failure and itchy skin rashes. Physical examination showed that the patient was moderately pale and had generalized oedema with discrete erythematous, papular lesions over different parts of the body. Serum for tissue transglutaminase (IgA) antibody was raised. Duodenal biopsy was obtained and histopathological diagnosis was compatible with coeliac disease. The patient was treated with supportive management and was advised for life long gluten free diet. The patient improved within short period after withdrawal of gluten from diet. [J Shaheed Suhrawardy Med Coll, 2013;5(1):55-58]
\end{abstract}

Keywords: gluten, recurrent diarrhoea, growth failure, skin rashes, Anti tissue transglutiminase, duodenal biopsy

Received: July 2012; Revised: March 2013; Accepted: May 2013

\section{Introduction}

Coeliac disease is also known as gluten-sensitive enteropathy, non-tropical sprue, coeliac sprue or gluten intolerant enteropathy ${ }^{1}$. It is a chronic digestive disorder found in genetically susceptible individuals who experience a toxic immune response when they ingest gluten ${ }^{1}$. Almost all people with coeliac disease have either the variant HLA-DQ2 allele or less commonly the HLADQ allele8. Furthermore, around 5\% of those people who develop coeliac disease do not have typical HLA-DQ2 or HLA-DQ8 alleles ${ }^{2}$. In Italy about 1 in 250 people and in Ireland about 1 in 300 people have coeliac disease ${ }^{3}$. A study of over 13,000 subjects in USA demonstrated the prevalence of 1 in every 133 Americans $^{3}$. Coeliac disease is most common in Caucasians; however it has been diagnosed in Asians from India and Pakistan ${ }^{3}$. It is rarely diagnosed in Japanese, Chinese or Africans ${ }^{4}$. This reflects a much lower prevalence of the genetic risk factors, such as HLA DQ8. Because of the genetic component of the disease, it is found in 5 to $15 \%$ of siblings and offspring having coeliac disease ${ }^{4}$. There is $70 \%$ concordance among identical twins ${ }^{4}$. Coeliac disease is more prevalent in women than in men ${ }^{5}$. Population studies indicate that a large proportion of coeliacs remain undiagnosed ${ }^{6}$. Likely the largest obstacle to diagnose coeliac disease is the failure to consider and test for the condition ${ }^{6}$. The authors have found academic interest to report this case as because detailing the clinical characteristics and investigations have given better information of the disease which allowed it to diagnose with accuracy.

\section{Case Report}

A 6-year-old girl of non-consanguineous parents was admitted in the Department of Paediatrics at Shaheed Suhrawardy Medical College and Hospital, Dhaka on October 2012 with the history of recurrent diarrhea for the last one year, having rashes all over the body for 1 month and generalized swelling for 15 days. Each episode of diarrhoea usually persisted for 2-3 days. The stool volume was large in amount with foul smelling and mostly watery,

1. Dr. Nazma Begum, Assistant Professor, Department of Paediatrics, Shaheed Suhrawardy Medical College \& Haspital, Dhaka

2. Prof. Soofia Khatoon, Professor, Department of Paediatrics, Shaheed Suhrawardy Medical College \& Haspital, Dhaka

3. Dr. Subrata Deb, Medical Officer, Department of Paediatrics, Shaheed Suhrawardy Medical College \& Haspital, Dhaka

4. Dr. Shamima Sultana, Medical Officer, Department of Paediatrics, Shaheed Suhrawardy Medical College \& Haspital, Dhaka

\section{Correspondence}

Dr. Nazma Begum, Assistant Professor, Department of Paediatrics, Shaheed Suhrawardy Medical College, Sher-E-Bangal Nagar, Dhaka, Bangladesh; Contact No: 01819242374; E- mail: nazmabegum29@ymail.com 
mixed with mucous without blood. The loose motion was not associated with abdominal pain, cramp or vomiting. Most often the loose motion subsided spontaneously and sometimes with medication. Rashes were erythematous and itchy. The swelling first appeared in the leg and subsequently involved face and abdomen. The patient had no history of fever, jaundice, haematuria, dysuria, respiratory distress and effort intolerance during this period of illness. The patient had good appetite and her diet was adequate. Her face was puffy and was moderately pale and had generalized oedema.



Figure I: Distended abdomen with skin changes

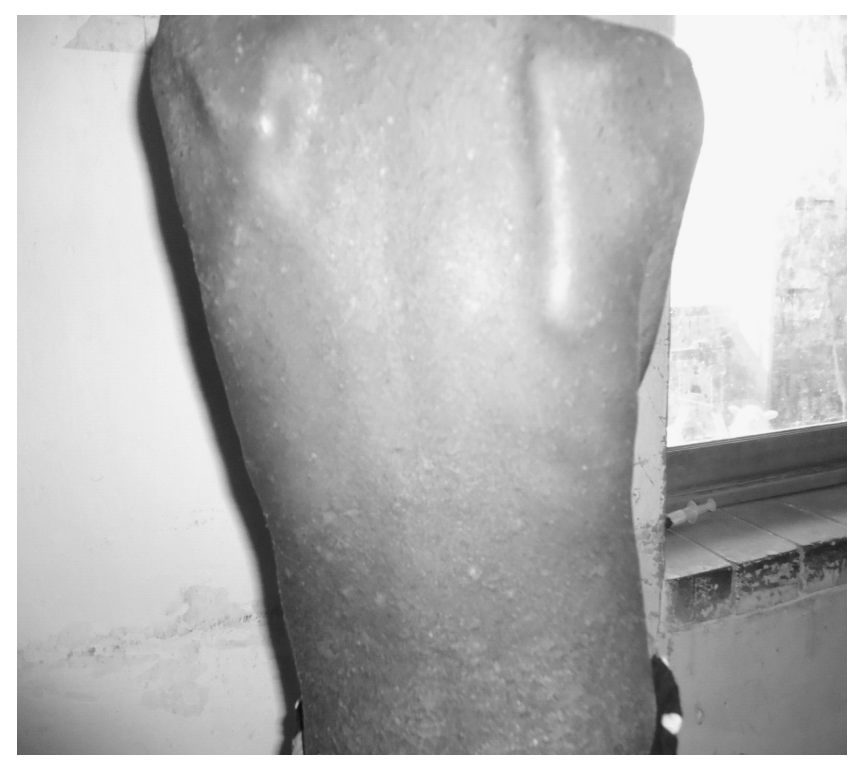

Figure II: skin changes over trunk

The girl was moderately wasted (Weight for Height $Z$ score -2.4) and stunted (Height for age $Z$ score-2.9). She had multiple, minute, discrete, follicular, erythematous, scaly, papular lesion involving the trunk and upper extremities. Her knee, ankle and dorsal aspect of the foot showed erythematous, swollen, scaly and crusted plaques. Hair was hypopigmented, sparse and lusterless. Urine for albumin was nil. Abdomen was distended; ascites present but had no organomegaly (Figure 1,2). Other systems revealed no abnormalities. Laboratory investigation showed reduced haemoglobin $(7 \mathrm{gm} / \mathrm{dl})$ with raised total WBC count $(11,000 / \mathrm{cmm})$. Peripheral blood film revealed microcytic hypochromic anaemia. Her urine for routine and microscopic examination, twenty four hours urinary total protein $(0.15 \mathrm{~g})$ and serum creatinine $(0.3 \mathrm{mg} / \mathrm{dl})$ level were normal. Liver function test showed normal serum ALT $(18 \mathrm{U} / \mathrm{L})$ and prothrombin time $(15 \mathrm{sec})$ with decreased serum albumin $(1.5 \mathrm{gm} / \mathrm{dl})$.

Ultrasonogram of abdomen revealed moderate ascites with bilateral pleural effusion. Her chest X-ray was normal and tuberculin test was negative. Serum for anti tissue transglutaminase (Anti-tTG) IgA was raised $(72.5 \mathrm{u} / \mathrm{ml})$. Upper GIT endoscopy revealed normal findings. Biopsy was taken from distal duodenum. Histopathology from biopsy material showed intraepithelial lymphocytes and fat globules; the lamina propria showed increased number of lymphocytes and crypt hyperplasia. The villi were normal in height and number (Figure 3,4). Based on above clinical manifestations like recurrent diarrhoea, skin manifestations, pallor and growth failure, raised serum anti-tTG and biopsy findings, the patient was diagnosed as a case of coeliac disease. By clinical and biochemical exclusion of common causes like renal, hepatic, cardiac and protein energy malnutrition, generalized oedema, ascites and hypoalbuminemia was considered due to protein losing enteropathy which is a common complication of coeliac disease. The girl was managed supportively with protein rich diet, antibiotic, blood and fresh frozen plasma transfusion, albumin infusion, oral zinc, zinc paste, vitamin $A$ and folic acid supplementation. Specific management for celiac disease was given by advising lifelong gluten free diet. Her oedema and ascites subsided and skin condition improved within short period after initiation of gluten free diet. The patient was advised for serum anti-tTG after two month.

\section{Discussion}

Coeliac disease has a wide spectrum of gastrointestinal and extraintestinal manifestation. Age at presentation may range from 6 months to more than 85 years. Approximately $20 \%$ of cases occur in patients older than 60 years ${ }^{7}$. Infants and older children usually present with impaired growth, diarrhoea and abdominal distension. The main extraintestinal manifestations of celiac disease in children are iron deficiency anaemia, delayed puberty, short stature, dermatitis herpetiformis and other skin disorder, chronic hepatitis, arthritis and arthralgia, osteopenia, rickets, neurological and psychiatric disorder ${ }^{8}$. This patient who was diagnosed as a case of coeliac disease was a female of 6 year old. She had recurrent diarrhoea, growth failure, moderate pallor and skin manifestations. Duodenal biopsy 
remains the gold standard in diagnosing coeliac disease according to North American Society for Paediatric Gastroenterology, Hepatology and Nutrition protocol ${ }^{9}$, which also joined the European Society of Paediatric Gastroenterology, Hepatology and Nutrition ${ }^{10}$.

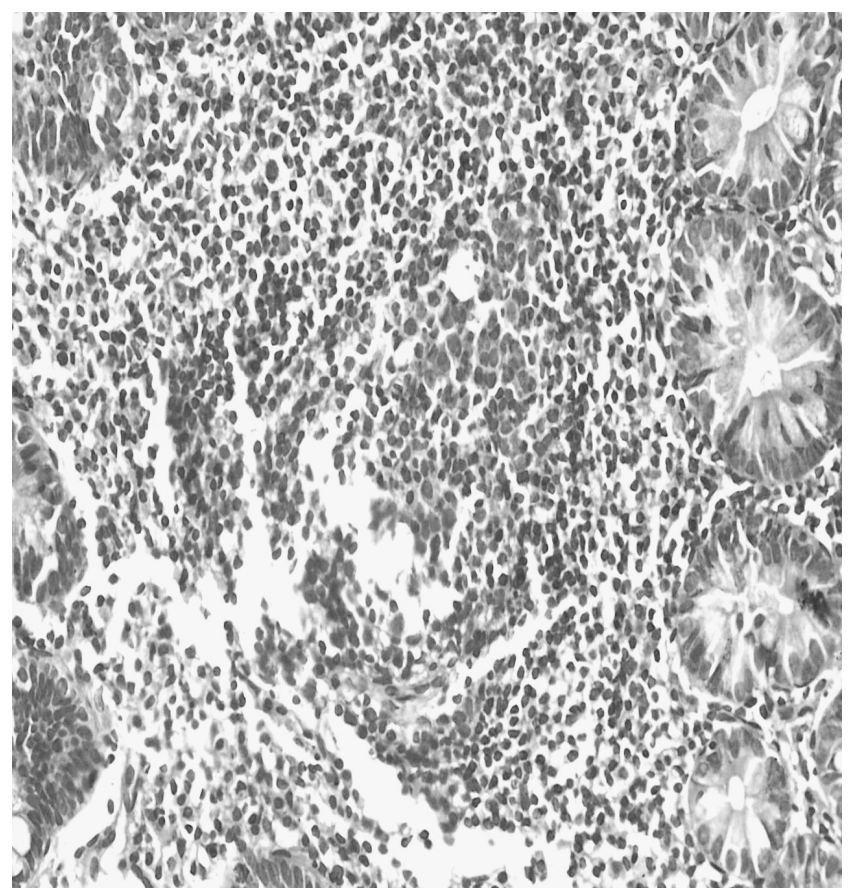

Figure III: Histopathology shows Lymphocyte infiltration in the lamina propria

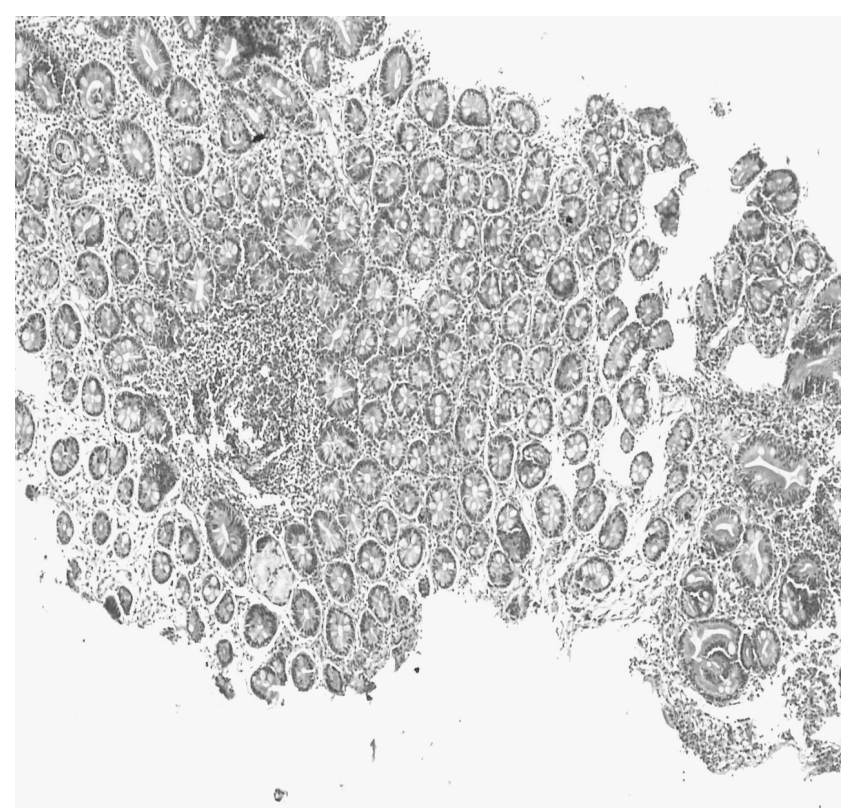

Figure IV: Histopathology shows crypt hyperplasia

Catassi and Fasano ${ }^{11}$ recently proposed a new diagnostic algorithm, which could confirm diagnosis of coeliac disease if at least 4 of the 5 criteria are positive which are typical symptoms of coeliac disease, serological positivity of immunoglobulin classes, a class of coeliac diseasespecific antibodies at a high titre, human leukocyte antigens DQ2 or DQ8 and diagnosis of coeliac disease by the biopsy of the small intestinal mucosa and the response to a gluten-free diet. The IgA endomysium (EMA-IgA) and tissue transglutaminase (TTG-IgA) tests are both highly sensitive and highly specific, with values for both parameters exceeding $96 \%$ in most studies ${ }^{9}$. The classic histological changes occur in the small intestine termed the Marsh classification are increased intraepithelial lymphocytes (type 1), crypt hyperplasia (Type 2) and villous atrophy (type 3$)^{12}$. The studied case fulfilled 4 positive criteria like typical symptoms, IgA antibodies, anti tTG in high titre and biopsy findings with response to gluten free diet. The histological change of small intestine was in type 2. Human leukocyte antigens DQ2 or DQ8 was not possible. Mustalahti et $\mathrm{al}^{13}$ conducted a study of 29,212 participants in four European countries and recommended performing intestinal biopsy only in those patients positive for serology testing. Once diagnosis of coeliac disease has been established and gluten free diet instituted, serologic markers are useful for monitoring response as well as adherence to the diet. With dietary compliance serologic markers diminish by 6 weeks and may be undetectable by 6 months ${ }^{14}$.

\section{Conclusion}

Coeliac disease is a treatable condition. A High index of suspicion is needed to identify the disease especially for the children present with recurrent or chronic diarrhoea, unexplained growth failure, weight loss and anaemia. Anti tissue transglutaminase is a valuable screening tool to diagnose the disease which is available in this country. Intestinal biopsy is indicated for serology positive cases.

\section{References}

1. Thompson T. Wheat starch, gliadin, gluten free diet. J Am Diet Assoc 2001; 101: 1456-9

2. Van HD, West J. Recent advances in coeliac disease. Gut 2006; 55 (7): 1037-46 3. Catassi C, Rätsch I, Gandolfi L, Pratesi R, Fabiani E, El Asmar R, etal Why is coeliac disease endemic in the people of the Sahara? Lancet 1999; 354 (9179): 647-84

4. Houlston RS, Ford D. Genetics of coeliac disease. QJM 1996; 89 (10): 737-43 5. Hischenhuber C, Creveln R, Jarry B, Mäki M, Moneret DA, and Romano A et al. Safe amounts of gluten for patients with wheat allergy or coeliac disease. Aliment Pharmacol 2006; 23 (5): 559-75

6. Zipser R, Farid M, Baisch D, Patel B, Patel D. Physician awareness of coeliac disease: a need for further education. J Gen Intern Med 2005; 20 (7): 644-6

7. Hanky GL, Hoimes GK. Coeliac disease in the elderly. Gut 1994; 35: 65-7 8. Catassi C, Fabiani E. The spectrum of coeliac disease in children. Clin Gastroenterol 1997; 11: 485-507

9. Hill ID, Dirks MH, Liptak GS. Guideline for the diagnosis and treatment of coeliac disease in children: recommendations of the North American Society for Pediatric Gastroenterology, Hepatology and Nutrition. J Pediatr Gastroenterol Nutr. 2005;40:1-19

10. Fasano A, Araya M, Bhatnagar S. Consensus guidelines. J Pediatr Gastroenterol Nutr. 2008;47:214-19

11. Catassi C, Fasano A. Coeliac disease diagnosis: simple rules are better than complicated algorithms. Am J Med. 2010; 123:691-93

12. Marsh MN, Hinde J. Inflammatory component of celiac sprue mucosa. Mast cells, basophils and eosinophils. Gastroenterology 1985; 89(1):92-101 
13. Mustalahti K, Catassi C, Reunanen A. The prevalence of coeliac disease in Europe: Results of a centralized, international mass screening project. Ann Med. 2010; 42:587-595
14. Sategna-Guidetti C, Pulitano R, Grosso S, Ferfoglia G. Serum IgA Antiendomysium antibody titre as a marker of intestinal involvement and diet compliance in adult coeliac sprue. J Clin Gaastroenterol 1993; 17:123-7 